\title{
Spinal tuberculomas mimicking spinal dural arteriovenous fistula: A case report
}

\author{
Jyoti Sureka, Varsha Mary Khalkho, Binita Riya Chacko
}

\begin{abstract}
Introduction: Tuberculosis is a very common disease in developing countries and has been found to affect almost all the parts of the body. We report the case of a patient who had spinal cord tuberculomas without evidence of symptoms of systemic tuberculosis. The lesions were located at the surface of lower thoracic cord and mimicked a spinal-dural arteriovenous fistula (SDAVF) on magnetic resonance imaging (MRI). Case Report: The patient was 45-year-old man who presented with a history of progressive paraparesis with a clinical suspicion of intramedullary tumor. First diagnosis was made as SDAVF on MRI. Then he underwent diagnostic and therapeutic digital substraction angiogram which was negative for the same. Again MRI was reviewed by a senior radiologist and a final diagnosis of spinal cord pial surface tuberculomas was made, confirmed by cerebrospinal fluid analysis and treated by appropriate anti-tubercular therapy. Conclusion: Tuberculosis can mimic a number of disease entitiles. It is important to be familiar with various a typical radiological presentations of tuberculosis.
\end{abstract}

Jyoti Sureka1, Varsha Mary Khalkho², Binita Riya Chacko³

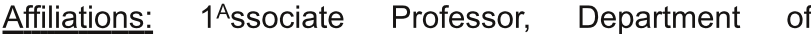
Radiology, Christian Medical College and Hospital, Vellore, Tamil Nadu, India; ${ }^{2}$ Tutor, Department of Radiology, Christian Medical College and Hospital, Vellore, Tamil Nadu, India; ${ }^{3}$ Assistant Professor, Department of Radiology, Christian Medical College and Hospital, Vellore, Tamil Nadu, India

Corresponding Author: Jyoti Sureka, Vellore, Tamil Nadu 632004, India: Ph: +919894584953; Fax: +91 041 62232035; Email: drjyoticmch@rediffmail.com

Received: 28 May 2012

Accepted: 29 July 2012

Published: 01 January 2013
Keywords: Tuberculoma, Spinal dural, Arteriovenous malformation

$$
* * * * * * * * *
$$

Sureka J, Khalkho VM, Chacko BR. Spinal tuberculomas mimicking spinal dural arteriovenous fistula: A case report. International Journal of Case Reports and Images 2013;4(1):28-31.

$* * * * * * * * *$

doi:10.5348/ijcri-2013-01-253-CR-7

\section{INTRODUCTION}

Tuberculosis (TB) is a very common disease in developing countries and has been found to affect almost all the parts of the body. It can affect any organ or organ system of the body. Tuberculosis primarily affects the chest and can involve multiple extrapulmonary sites like heart, bones, joints, gastrointestinal system, genitourinary system, central nervous system, eyes, etc. Spinal TB accounts for more than half of the musculoskeletal TB. The extradural form of spinal TB is most common [1]. Uncommonly, it can present as arachnoidal, intradural extramedullary and intramedullary form. Spinal intraduralintramedullary tuberculoma is extremely rare entity can give rise to a variety of clinical and radiologic features which can mimic a number of other spinal cord lesions particularly intramedullary tumors $[2,3]$. We report the case of a patient who had spinal cord tuberculomas without evidence of symptoms of systemic tuberculosis. The lesions were located at the surface of lower thoracic cord and mimicked a spinal dural arteriovenous fistula (SDAVF) on magnetic resonance imaging (MRI). 


\section{CASE REPORT}

A 45-year-old male presented to the neurology out patient department (OPD) with complaints of back pain and progressive lower limb weakness since six months. There were no bowel or bladder difficulties. On physical examination, there was spine tenderness over the mid and lower thoracic spine, muscle weakness and abnormal reflexes in lower limbs. Laboratory investigations revealed positive results for human immunodeficiency virus (HIV) and hepatitis B virus (HBV). However, complete blood picture, ESR, Creactive protein and other routine blood examinations were within normal limits. Chest X-ray was also normal. Based on clinical findings possibility of intramedullary tumor was considered. Patient underwent gadoliniumenhanced MRI of spine. Sagittal and coronal T2weighted MRI of thoracolumbar spine showed multiple tortuous flow voids along the surface of mid and lower thoracic spinal cord. The lower thoracic cord was also slightly enlarged and showed increased intramedullary signal intensity (Figure 1). Diagnosis of SDAVF with edema or ischemia of cord secondary to venous hypertension was made. For further management, patient underwent diagnostic and therapeutic selective spinal DSA. The angiogram did not reveal any feeding vessels or nidus to suggest arteriovenous fistula (AVF) (Figure 2A-B). MRI images were further reviewed by a senior radiologist with a referring doctor. The coronal gadolinium-enhanced T1-weighted images showed multiple, small, almost similar sized ring and nodular enhancing lesions along the pial surface of the cord with central T2 hypointensity which appeared as a flow void on T2-weighted sagittal and coronal images (Figure 3). There was no focal enhancing lesion or abnormal enhancement in the region of high signal intensity of the lower thoracic spinal cord. Considering the immunocompromised status, a final diagnosis of spinal cord pial surface tuberculomas with associated cord edema or myelitis was made. MRI of the brain did not reveal any lesion. Patient underwent CSF analysis which grew acid-fast bacilli and isolated species was Mycobacterium tuberculosis and hence the diagnosis was confirmed and first line anti-tubercular therapy (ATT) was started. The patient responded well to ATT.

\section{DISCUSSION}

Central nervous system TB is commonly seen in tropical countries [4]. In immunocompromised individuals, the presentation of tubercular lesions may be atypical and can result in delayed diagnosis [5, 6]. Imaging plays an important role in recognition of these atypical cases that mimic other neurologic conditions thus helps in early diagnosis and treatment, which otherwise may result in irreversible neurological sequel [4-6]. A few case reports talk about the isolated meningeal or spinal tuberculoma mimicking spinal tumor. However, spinal TB mimicking a SDAVF not yet reported in literature. Extradural form is the most common while arachnoiditis, intradural and intramedullary tuberculomas are uncommon presentation of spinal TB [4, 7]. This atypical form of TB can occur as a direct extension from the vertebrae, as a downward extension of intracranial tubercular meningitis, and less commonly as tuberculous lesions primarily developing in spinal meninges [5, 8]. MRI is the imaging modality of choice for these lesions. Spinal cord TB, generally, present as intramedullary tuberculomas with or without myelitis and syrinx. Clinically as well as radiologically, intramedullary tuberculomas may be difficult to differentiate from space-occupying lesions such as primary and metastatic intramedullary spinal tumors and other chronic granulomatous diseases (sarcoidosis, histiocytosis and brucellosis) [9]. Commonly the intramedullary tuberculomas have specific MR features and can be diagnosed on imaging. It has a typical "target sign" on T2-weighted imaging, demonstrating low signal center (caseous material) surrounded by high signal rim (peripheral infective granulation tissue), which helps to differentiate tuberculoma from other intramedullary lesions $[10,11]$. On intravenous contrast study, these lesions show rounded nodular and ring like peripheral enhancement with non-enhancing center of the lesion. If the lesion has a typical appearance on MRI, and if the patient has systemic tuberculosis, diagnosis of tuberculoma can be made easily [9-11]. If the patient does not have systemic tuberculosis and has immunocompromised status, MRI features can be atypical as seen in our case and diagnosis can be difficult. In our case, all the lesions were of almost similar size and appeared as hypointense dots on the surface of cord on T2-weighted images and thus

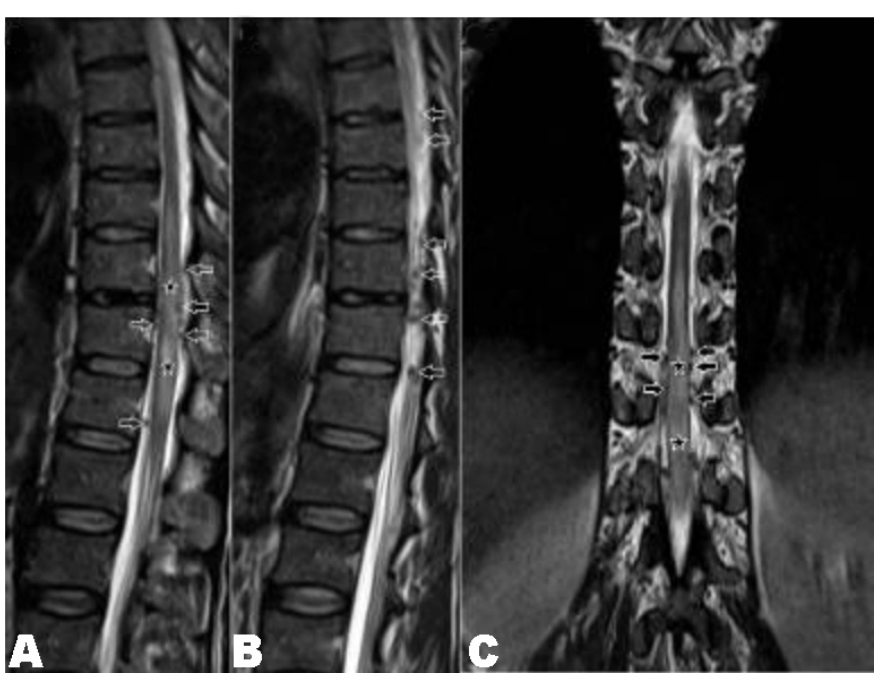

Figure 1: A 45-year-old male presented with progressive worsening of lower limb weakness since several months. T2weighted (A) mid, (B) para-sagittal, and (C) coronal MRI of mid and lower thoracic spine demonstrate diffuse, lower thoracic spinal cord, high signal intensity and mild swelling (stars) suggesting cord edema with multiple tortuous hypointense dots (open arrows in sagittal and black arrows in coronal images) giving appearance of flow voids along the surface of mid and lower thoracic cord. 

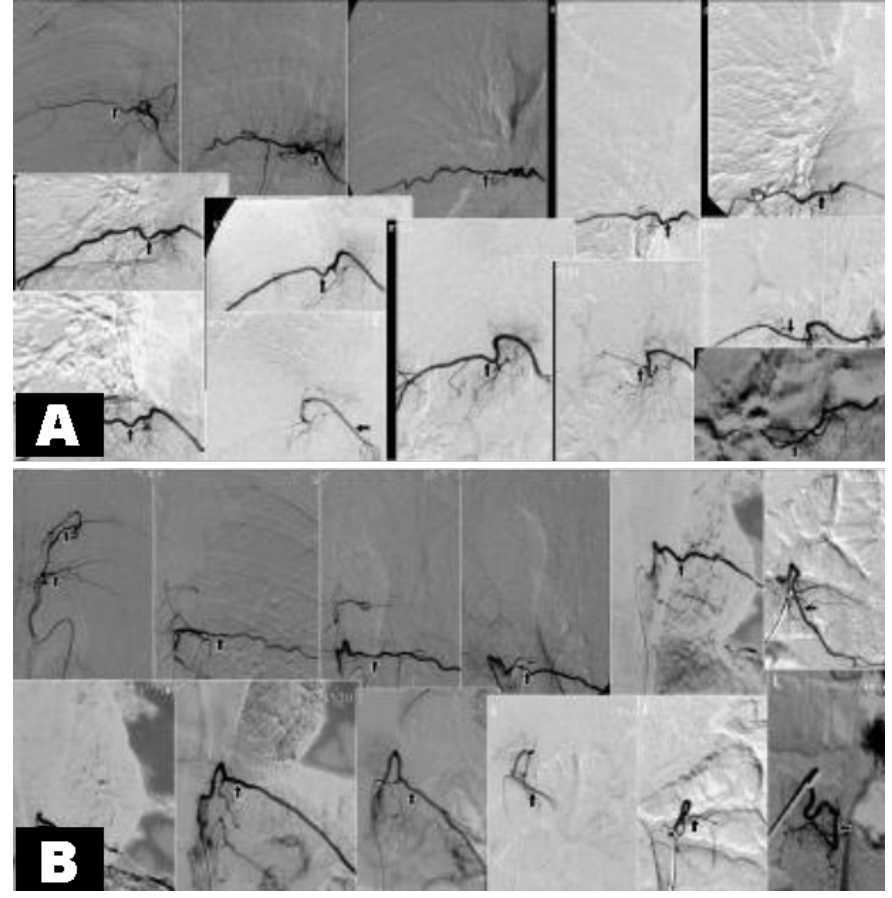

Figure 2: A 45-year-old male presented with progressive worsening of lower limb weakness since several months. Spinal angiogram with selective runoff of (A) right thoracolumbar arteries (black arrows) from $\mathrm{T} 4$ to L4, and (B) left thoraco-lumbar arteries (black arrows) T2 to L4, did not reveal any pial feeder vessel or other evidence of spinal cord arteriovenous malformation.

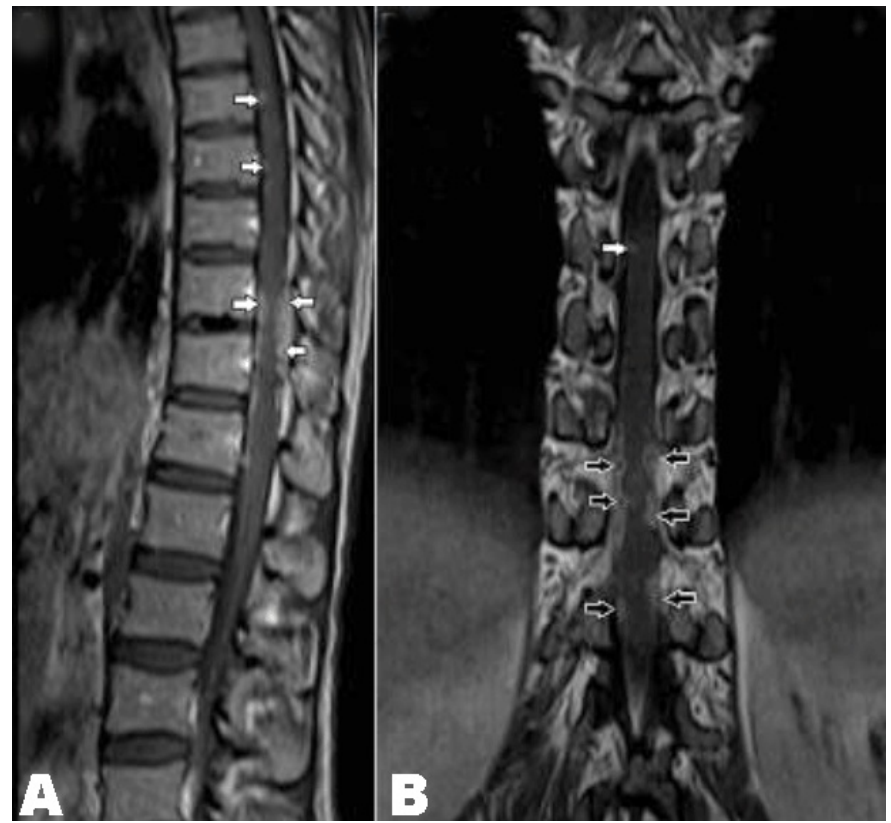

Figure 3: A 45-year-old male presented with progressive worsening of lower limb weakness since several months. T1weighted post gadolinium (A) sagittal, and (B) coronal MRI of mid and lower thoracic spine demonstrated multiple small nodular (white arrows) and ring (black arrows) enhancing lesions of almost same size along the surface of thoracic cord. No enhancement of cauda equina nerve roots or within the cord substance in the region of high signal intensity was observed. mimicked SDAVF. Further cord swelling, hyperintensity and involvement of lower thoracic cord again supported the diagnosis of SDAVF. During the initial MRI evaluation, gadolinium enhanced imaging was overlooked and thus the lesion was mistakenly diagnosed as SDAVF and patient had to undergo DSA. Gadolinium enhanced images clearly demonstrated ring and nodular enhancement of all the T2 hypointense lesions thus helped in making the final diagnosis of tuberculomas.

\section{CONCLUSION}

Tuberculosis has a variety of clinical and radiologic features and can mimic a number of other disease entities. Therefore it is important to be familiar with the various atypical radiological presentations of TB particularly in immunocompromised patients to ensure early, accurate diagnosis and treatment and to avoid unnecessary invasive and costly investigation like DSA. Spinal cord tuberculomas can mimic SDAVF if the lesions are multiple, very small and similar in size and are located at the pial surface of the cord. The associated cord swelling and hyperintensity can simulate venous hypertension associated with SDAVF. Gadolinium enhanced imaging is extremely important. The coronal T1-weighted post contrast imaging can show enhancing periphery and non-enhancing center of the lesion which is not seen in hypertrophied vessels of SDAVF.

$$
* * * * * * * * *
$$

\section{Author Contributions}

Jyoti Sureka - Substantial contributions to conception and design, Acquisition of data, Analysis and interpretation of data, Drafting the article, Revising it critically for important intellectual content, Final approval of the version to be published Varsha Mary Khalkho - Analysis and interpretation of data, Revising it critically for important intellectual content, Final approval of the version to be published Binita Riya Chacko - Analysis and interpretation of data, Revising it critically for important intellectual content, Final approval of the version to be published

\section{Guarantor}

The corresponding author is the guarantor of submission.

\section{Conflict of Interest}

Authors declare no conflict of interest.

\section{Copyright}

(C) Jyoti Sureka et al. 2013; This article is distributed under the terms of Creative Commons Attribution 3.0 License which permits unrestricted use, distribution and reproduction in any means provided the original authors and original publisher are properly credited. (Please see www.ijcasereportsandimages.com/copyright-policy.php for more information.) 


\section{REFERENCES}

1. Harisinghani MG, McLoud TC, Shepard JA, Ko JP, Shroff MM, Mueller PR. Tuberculosis from head to toe. Radiographics 2000;20(2):449-70.

2. Shah IU, Siddiqui UT, Imran M, Ashraf J, Mazhar S, Ghori SA. Intramedullary spinal tuberculoma. J Coll Physicians Surg Pak 2012;22(1):48-9.

3. Mohit AA, Santiago P, Rostomily R. Intramedullary tuberculoma mimicking primary CNS lymphoma. J Neurol Neurosurg Psychiatry 2004;75(11):1636-8.

4. Gupta RK, Kumar S. Central nervous system tuberculosis. Neuroimaging Clin $\mathrm{N}$ Am 2011;21(4):795-814.

5. Sree Harsha CK, Shetty AP, Rajasekaran S. Intradural spinal tuberculosis in the absence of vertebral or meningeal tuberculosis: a case report. J Orthop Surg (Hong Kong) 2006;14(1):71-5.

6. Huebner RE, Castro KG. The changing face of tuberculosis. Annu Rev Med 1995;46:47-55.
7. Hristea A, Constantinescu RV, Exergian F, Arama V, Besleaga M, Tanasescu R. Paraplegia due to nonosseous spinal tuberculosis: report of three cases and review of the literature. Int $J$ Infect Dis 2008;12(4):425-9.

8. Poon TL, Ho WS, Pang KY, Wong CK. Tuberculous meningitis with spinal tuberculous arachnoiditis. Hong Kong Med J 2003;9:59-61.

9. Kadir KOTIL, Necmettin GUZEL. Primary Intramedullary Tuberculoma of The Spinal Cord Mimicking To Spinal Cord Tumor. Journal of Neurological Sciences (Turkish) 2006;23(1):063-7.

10. Lu M. Imaging diagnosis of spinal intramedullary tuberculoma: case reports and literature review. J Spinal Cord Med 2010;33(2):159-62.

11. Jena A, Banerji AK, Tripathi RP, et al. Demonstration of intramedullary tuberculomas by magnetic resonance imaging: a report of two cases. Br J Radiol 1991;64:555-7.
Access full text article on other devices

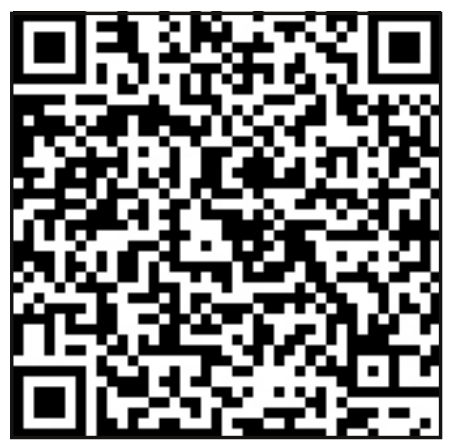

Access PDF of article on other devices

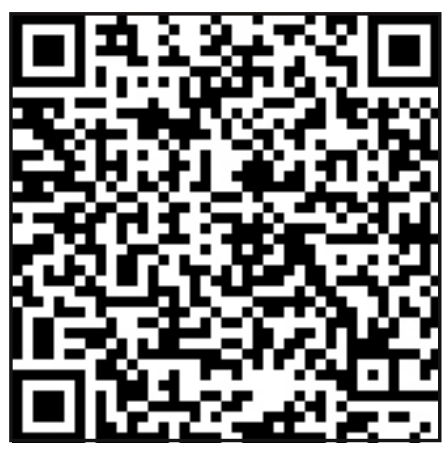

